\title{
Assisted tennis teaching effects: Experimental analysis based on statistics methods
}

\author{
Chang Le \\ Faculty of sports science \\ Ningbo University \\ Ningbo, China \\ e-mail: 597670248@qq.com \\ Li Yuntao \\ Faculty of sports science \\ Ningbo University \\ Ningbo, China \\ e-mail: luoyinnb@qq.com
}

\author{
Lian Wenlan \\ Faculty of sports science \\ Ningbo University \\ Ningbo, China \\ e-mail: lianwenlan@163.com
}

\begin{abstract}
Modern teaching theory has already penetrated into each discipline teaching, many physical education teachers also take it as guidance; while computer-assisted teaching possesses interesting features with its own special functions, and it has great worth in concentrating students' attentions and stimulating their motions. In order to improve tennis teaching quality and propel tennis education reform, this paper designs 3 months total 24 courses computer-assisted teaching experiments according to tennis teaching features and objectives so as to explore computerassisted teaching advantages which over that of traditional teaching through data generated before and after experiment as well as during experiment process, and provide theoretical basis for tennis education reform. In this paper, firstly state modern physical education objects transferring direction and tennis education features, then analyze tennis forehand strokes technical features, finally verify such teaching method advantages by comparing with traditional teaching through computer-assisted teaching experiment design, experimental data and experimental result based on statistics analysis.
\end{abstract}

Keywords-Computer-assisted teaching; SPSS statistics software; normal distribution; tennis education

\section{INTRODUCTION}

After entering into 21st century, people's living quality has been greatly improved. Sports has already become one part of life, entertainment sports weight has been increasing, sports and lifelong sports has been further combined .Sports event learning during university mainly is transferred to life sports, entertainment sports and cultural sports these aspects. Tennis as one of the seldom access lifelong sports event in middle school stage, its education has some problems. So as to propel the sport development, this paper makes research on tennis teaching objectives, modern tennis teaching model as well as its combination with computer-assisted teaching to explore tennis education reform directions through research process and result in the paper.

For research of combined tennis teaching with computer-assisted teaching, many people have made efforts; their teaching ideas and experimental result continuously propel tennis teaching as well as other physical education modernization development. Among them, Tong Yan-Hua Makes research on traditional tennis teaching and "static\& dynamic combination" teaching method as well as teaching effects with high university 6 groups students in tennis selective course in 2011, and gets that adopts "static \& dynamic combination" teaching method not only can improve initial tennis learning students learning efficiency, hitting success rate and motions normalization, but also can reduce teachers teaching workload [1]; Wang Hao Implementation of education reform by social development, apply exploring teaching model to improve students positivist and creative ideas, and analysis its application in tennis teaching[2]; Kong Xin-Liang According to computer-assisted teaching theory and its method application in tennis teaching content design as well as schedule arrangements, provides theoretical basis for optimizing tennis teaching structure through contrast analysis research on experimental results between traditional teaching method and computer-assisted teaching [3]

First task for school teaching activities is to cultivate student self-learning ability and creative talent. Transfer teaching importance into first task, improve teaching efficiency with school as unit, make students the master of learning, realize learning individualization, let teachers fully play student learning leading role, first task reflects modern learning process objective law. Cultivate student self-learning ability and develop their creative talent is the basic guarantee to improve teaching quality that is the start point and end-result of school education reform [4].

Tennis course is one of the important courses in normal university physical education teaching, its specialty 
reflects that most of students never access to it in middle school stages, which occurs to incoherent exercising times in tennis course in case itself has less group hour, causing student trained technical motions cannot be defined. Comparing with other sports special events, tennis has remarkable difference that is many people participated while court seriously insufficient. Besides, student physical quality, psychological quality, coordinate ability and technical motions all have great differences, these differences indicate in the three aspects as following.

Based on above traditional tennis teaching shortcomings, this paper puts forward one teaching pattern as computer-assisted teaching, the pattern is the multimedia teaching that has been appeared as earliest as 1980s, while computer technology has gotten rapidly development and prevailed in 1990s, multimedia computer has already replaced previous multiple teaching medias in comprehensive using ,therefore common mentioned multimedia teaching specially refers to teaching activities process by utilizing multimedia computer and with the support of prepared multimedia teaching software beforehand, which is called as computer-assisted teaching (CAT).

To enrich tennis teaching pattern and obtain improvement of teaching effect, it is need to explore the merits between computer-assisted teaching and traditional 5 segments teaching method and design teaching experiments according to tennis teaching features and teaching objectives, so that can get computer-assisted teaching advantages and tennis teaching pattern reform directions through analysis of teaching experiment result [5].

This paper based on previous analysis, makes research on integrating points of modern tennis teaching objectives and computer-assisted teaching, and designs 3 months 24 courses teaching experiments so as to explore computerassisted teaching's rationality in tennis teaching application.

\section{METHODS}

Racket trajectory, angle and speed are three mechanical factors that should be taken into consideration to succeed hitting. When racket face is vertical to court or pull racket at 10 degree and prepare for forehand hitting, racket trajectory have great changes before and after hitting, Table 1 shows angles that racket forms to ground conditions in flat hitting, top spin hitting and top spin slowing .

TABLE I. TABLE OF RACKET ANGLES BEFORE AND AFTER 3 KINDS OF HITTING

\begin{tabular}{rcc}
\hline Hitting way & Before hitting & After hitting \\
Flat hitting & $35^{\circ}$ & $50^{\circ}$ \\
Top spin hitting & $35^{\circ}$ & $50^{\circ}$ \\
Top spin & $50^{\circ}$ & $70^{\circ}$ \\
\hline
\end{tabular}

Comparing with flat hitting, earlier fast embrace ball before hitting and in early stage of follow through should be done during top spin hitting, or in hitting, reduce racket speed in forward direction and increase racket speed in upward direction, follow through is in the stage after hitting; When players shift location and make preparation for next hitting, upper limbs gradually get slower, upper limbs largely internal rotation before and after hitting usually means follow through is across one side of body. From the perspective of technical analysis, when coach corrects players' one item technique, its location in train court is very important.

Before experiment experimental group and control group two groups students forehand stroke motion levels diagnostic evaluation results is as Table 2 shows.

TABLE II. TABLE OF RACKET ANGLES BEFORE AND AFTER 3 KINDS OF HITTING

\begin{tabular}{cccc}
\hline Mechanical elements & A & B & C \\
\hline Experimental group & 12 & 18 & 16 \\
\hline Control group & 11 & 20 & 15 \\
\hline
\end{tabular}

Motion teaching sequence is not definitely the motion structure sequence features, while it should guide by cognitive psychological features. The effect of tennis forehand stroke technical motion firstly is up to motion posture, therefore form into good motion posture is basic requirement of tennis technical teaching, cognitive psychology thinks that motion techniques forming firstly is vision dominates, and then transitionally change into kinesthesia control takes the principal. To verify motion teaching sequence influences on student motion presentation, function forming, Table 3 shows experimental group and control group scores condition in description of motions, from which each indicator full score is 10 scores, when description is fully correct then get 10 score, the maximum error in description get 0 score.

TABLE III. TABLE OF STUDENTS' MOTION DESCRIPTION EVALUATION RESULT COMPARISON

\begin{tabular}{cc}
\hline $\begin{array}{c}\text { indicator } \\
\text { content }\end{array}$ & $\begin{array}{c}\text { average value of } \\
\text { experimental }\end{array}$ \\
group \\
$\begin{array}{c}\text { Balance description } \\
\text { Forward swing racket starting } \\
\text { point description }\end{array}$ & 7.5 \\
$\begin{array}{c}\text { Backward swing racket starting } \\
\text { point description }\end{array}$ & 8.6 \\
$\begin{array}{c}\text { Right leg grounding motion } \\
\text { racket trajectory } \\
\text { description }\end{array}$ & 8.3 \\
$\begin{array}{c}\text { Forearm internal rotation } \\
\text { motion description }\end{array}$ & 8.9 \\
$\begin{array}{c}\text { Racket technical motion } \\
\text { description }\end{array}$ & 8.1 \\
$\begin{array}{c}\text { Error value between } \\
\text { subjectivity and actual }\end{array}$ & 8.6 \\
\hline
\end{tabular}

Physical education course density is called comprehensive density; it refers to proportion that each teaching activity reasonable applying time covers total course time in course as well as time proportion among each activity. Due to course activity forms are different ,measurement of course training density according to different activity items features can be divided into student training time, teacher guiding time, teacher observing and helping time, teacher organizational measure time, rest time and unreasonable time such 5 items. In multimedia computer-assisted teaching process, 
successively teaching new courses to experimental group and control group by random selection, evaluation its conformity according to above 5 kinds of time indicators, course density statistics and chart steps are as following 4 steps.

STEP1 Add each activity practice, such as teacher explanation, demonstration and individual guidance etc.

STEP2 Divide one course time into seconds, total 5400 seconds.

STEP3 Calculate one item consumed time and total course time proportion.

STEP4 According to proportions that calculated, get statistic check list through SPSS.

\section{RESULTS}

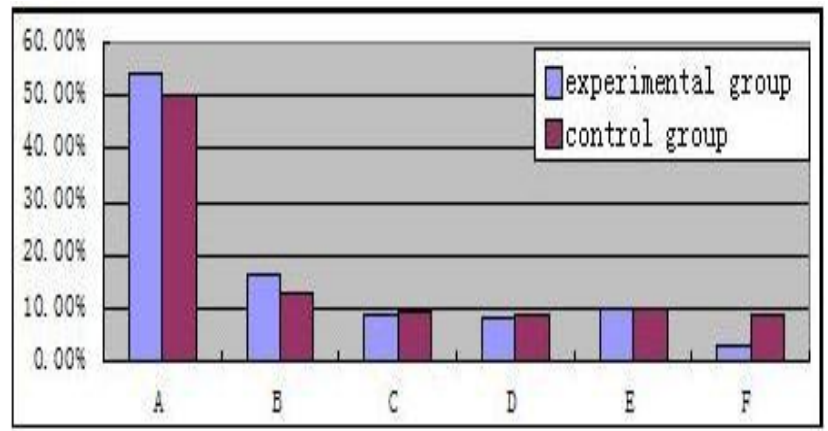

Figure 1. Experimental group and control group course training time density column diagram

Lots of indicators and factors decide tennis teaching quality. At first according to physical education basic features and physical education objectives, list out each factor that influences on physical education course quality, make respectively paired comparison of each indicator that selected by experts assessment, finally get each factor weight to tennis teaching course quality, formulate 6 first level indicators and 12 second level indicators in evaluation table and measure all Table's indicators with quantized value.

$$
G=\sum w_{i} C_{k}
$$

In formula (1), wi represents evaluation set affiliating ranking, $\mathrm{Ck}$ represents overall evaluation on teacher teaching quality, whole testers average score $\mathrm{X}$ computational method is as formula (2) shows.

$$
X=\frac{1}{n-2} \sum_{i=1}^{n-2} M_{i}
$$

In formula (2), $\mathrm{X}$ represents teacher evaluation final score, $\mathrm{M}$ represents each rater score, $\mathrm{n}$ represents people numbers that participate grade. Computational method of evaluation table total evaluation is as formula (3) shows

$$
X=\sum_{i=1}^{6} a_{i} x_{i}
$$

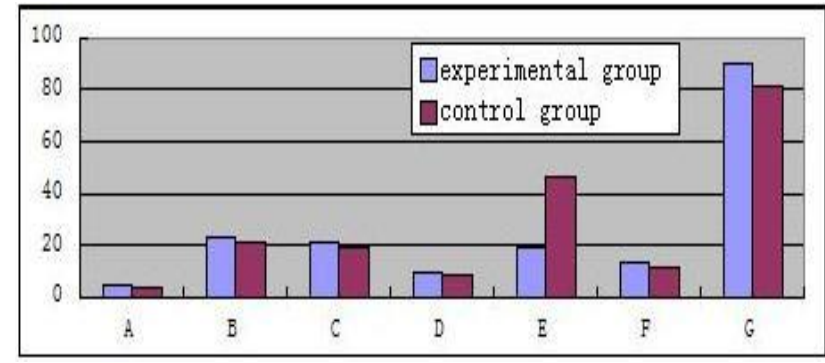

Figure 2. Tennis teaching course two group teaching quality score column diagram

From Fig .2, it can be known that experimental group teaching quality with computer-assisted teaching has obviously an advantage over control group with traditional teaching.

After 3 months total 24 courses teaching, carry out theory course test, the result is students in experimental group get highest score as 96, lowest score as 63 , average score as 80.9 , their standard deviation is 8.857; while students in control group get highest score as 94, lowest score as 55 , average score as 71.8 , their standard deviation is 9.256. According to teaching management regulation, in teaching test, it should conform to normal distribution theory, which means around $20 \%$ students arrive at excellent level, around $40 \%$ students arrive at good level, around $35 \%$ student arrive at qualified standard. Through experiment result handling, two group students average score is 76.38 , standard deviation is 10.1.Due to student theory score conforms to normal distribution, then apply standardization formula as formula (4) shows.

Since $20 \%$ student are required to arrive at excellent level, the excellent performance is $86,40 \%$ student are required to arrive at good level, the good performance is $73,35 \%$ student are required to arrive at qualified level, the qualified performance is 61.Apply above methods to handle two group students theoretical knowledge test scores with SPSS statistics, it can get conditions as Table 4 shows.

\begin{tabular}{|c|c|c|}
\hline & X 61 & $61 \times 73$ \\
\hline Experimental group & 0 & 12 \\
\hline Control group & 2 & 24 \\
\hline Difference & -2 & 12 \\
\hline
\end{tabular}

TABLE IV. EXPERIMENTAL GROUP AND CONTROL GROUP THEORETICAL TEST SCORE TABLE

From Table 4 data, it can get theoretical test two group students test scores column diagram number of people distribution conditions as Fig .3 shows.

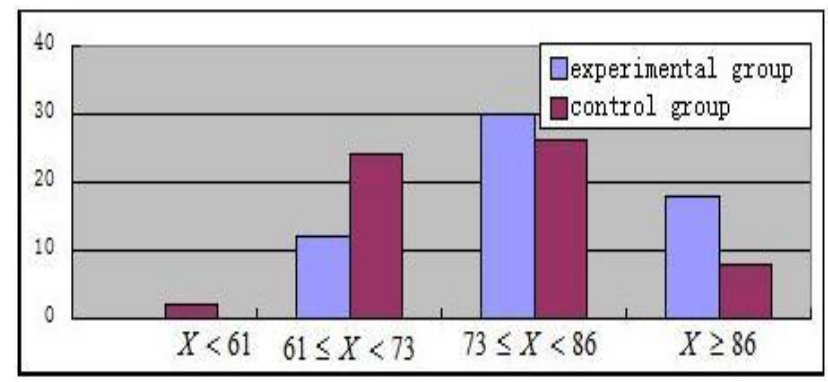

Figure 3. Experimental group and control group theoretical knowledge test result contrast column diagram 


\section{CONCLUSION}

This paper analyzed tennis teaching pattern features, stated modern physical education idea and tennis teaching objectives new era significance. Explored computerassisted teaching features together with this teaching method and new era tennis teaching integrating point. Designed computer-assisted teaching experiment targeted on tennis teaching, the experiment was composed of 120 people that total divided into experimental group and control group such two groups, made track investigation of 3 months total 24 courses, applied SPSS statistics software to make data analysis of traditional teaching and computerassisted teaching features before and after experiment as well as during experiment, got each factor features that computer-assisted teaching was over traditional teaching , and provided theoretical basis for tennis teaching reform.

\section{REFERENCES}

[1] Karoly P, Ruehlman LS. "Motivational implications of pain: Chronicity, psychological distress, and work goal construal in a national sample of adults". Health Psychol, vol. 5, pp. 383-390, 1996.
[2] Lewthwaite R. "Threat perception in competitive trait anxiety: The endangerment of important goals". J Sport Exerc Psychol, vol. 12 pp. 280-300, 1990.

[3] Lutz RS, Karoly P, Okun MA. "The why and the how of goal pursuit: Self-determination, goal process cognition, and participation in physical exercise". Psychol Sport Exerc, vol. 9, pp. 559-575, 2008

[4] MacKinnon DP, Lockwood CM, Williams J. "Confidence limits for the indirect effect: Distribution of the product and resampling methods". Multivariate Behav Res, vol. 39, pp. 99-128, 2004.

[5] Oettingen G, Pak H, Schnetter K. "Self-regulation of goal setting: Turning free fantasies about the future into binding goals". J Pers Soc Psychol, vol. 80, pp. 736-753, 2001.

[6] Gainforth CJ, Barg AE, Latimer KL. "An investigation of the theoretical content of physical activity brochures". Psychol Sport Exerc, Vol.12, pp. 615-620, 2011

[7] Devereux JM, Hastings RP, Noone SJ, Firth A, Totsika V. "Social support and coping as mediators or moderators of the impact of work stressors on burnout in intellectual disability support staff'" Res Dev Disabil, vol.30, pp.367-377, 2008.

[8] Conroy DE, Willow JP, Metzler JN. "Multidimensional fear of failure measurement: The Performance Failure Appraisal Inventory". J Appl Sport Psychol, vol.14, pp.76-90, 2002.

[9] Bueno J, Weinberg RS, Fernández-Castro J, Capdevila L. "Emotional and motivational mechanisms mediating the influence of goal setting on endurance athletes' performance". J Sport Exerc Psychol, vol.9, pp.786-799, 2008.

[10] Liu WN, Zhou CL. "Influence of goal setting on receiving successrate and self-control of table tennis players". China Sport Sci, vol.27, pp.57-63, 2007. 